\title{
On the lack of a clear-cut association between alpha-2-macroglobulin deletion and the risk of Alzheimer disease in Poland
}

\author{
Grażyna Michałowska-Wender ${ }^{1,2}$, Alicja Wawrzynek ${ }^{1}$, Grzegorz Rossa ${ }^{3}$, Wojciech Kozubski ${ }^{4}$, Mieczysław Wender ${ }^{2}$ \\ ${ }^{1}$ Laboratory of Neurogenetics, Department of Neurology, University of Medical Sciences, Poznań, Poland, ${ }^{2}$ Neuroimmunological Unit, \\ Mossakowski Medical Research Centre, Polish Academy of Sciences, Poznań, Poland, ${ }^{3}$ Regional Hospital for Neurological \\ and Psychiatric Diseases, Cibórz, Poland, ${ }^{4}$ Department of Neurology, University of Medical Sciences, Poznań, Poland
}

DOI: $10.5114 / f n .2014 .47842$

\begin{abstract}
Alzheimer disease $(A D)$ is a complex, multi-factorial disease with the potential involvement of several genes. Alpha-2macroglobulin (A2M) has been implicated in $A D$ on the basis of its ability to mediate the clearance and degradation of $\beta$-amyloid peptide. Nevertheless, it is not clear whether there are racial differences in frequency of polymorphisms of $A 2 M$ in $A D$. We examined a group of 50 unrelated patients from Poland (38 women and 12 men), who were diagnosed clinically as probably developing AD (according to the N1NCD3-ADR PA criteria). The patients were examined by a neurologist and a psychologist and had a CT or MRI scan of the brain. Fifty individuals of matched age, without any signs of dementia, were studied as a control group. DNA was extracted by a routine method from a blood sample. Amplification and genotyping at A2M was performed as described by Blacker et al. (1997). The genotypic distribution in A2M exon 18 in patients with AD and genotype TT in A2M exon 24 was similar to that in the controls. Significant differences were noted only in early onset $A D$ in males and for old onset disease in females. The deletions were found more frequently in $A D$; however, they were found in only a small proportion of studied patients. These findings indicate that $A 2 M$ is not the only biological candidate gene for $A D$ determination.
\end{abstract}

Key words: Alzheimer disease, alpha-2-macroglobulin, polymorphism.

\section{Introduction}

Alzheimer disease (AD) is a complex multi-factorial disease with the potential involvement of several genes. Alpha-2-macroglobulin (A2M) has been implicated in $A D$ on the basis of its ability to mediate the clearance and degradation of $\beta$-amyloid peptide. Nevertheless, it is not clear whether there are racial differences in frequency of polymorphisms of A2M in $A D$.
Association of $A 2 M$ deletion polymorphism with sporadic AD was reported in Korea [11] and in southern Italy [23]. Genetic association of A2M with AD was also noted in the Finnish elderly population [16]. Similar results were reported in the USA $[5,7,13]$. These data seem to support the view about susceptibility for $A D$, linked to $A 2 M$ polymorphism.

However, there are also many studies with negative results, including in Poland [21], Hungary [10], 
Japan [9], China [20], USA [22], Italy [17], Germany [3], France [8] and Sweden [6].

The discussed differences between various human populations may be explained by the known gene expression variability between different human populations, with the impact on disease susceptibility [14], and by biochemical individuality probably with potential relevance to AD [15].

The above, briefly presented differences regarding whether existing data point to an association between $A 2 M$ polymorphism and AD justify our interest in this problem.

\section{Material and methods}

We examined a group of 50 unrelated patients from Poland (38 women and 12 men), who were diagnosed clinically as probably developing $A D$ (according to the N1NCD3 - ADR PA criteria), including 35 patients with an onset of over 65 years of age (late $A D$ ) and 15 with an early $A D$ (onset before the $65^{\text {th }}$ year of age). The patients were examined by the neurologist and psychologist and had a CT or MRI scan of the brain. Fifty individuals of matched age, without any signs of dementia, were studied as control subjects.

DNA was extracted by a routine method from a $1 \mathrm{ml}$ EDTA blood sample. All patients were pseudosporadic ones, without evident familiar association. Amplification and genotyping at A2M was performed as described by Blacker et al. [5].

\section{Results}

The genotype and allelic distribution were compared between controls and patients with $A D$. In the control group the genotype WW in A2M exon 18 was detected in $74 \%$ of individuals. Heterozygous W/A was found in $24 \%$, and $\Delta \Delta$ was found in only $2 \%$ of control group individuals. Allelic distribution in the control group was $86 \%$ for $W$ and $14 \%$ for $\Delta$.

The genotypic distribution in $\mathrm{A} 2 \mathrm{M}$ exon 18 in patients with $A D$ was similar to that in the controls. The genotype WW was detected in 32 cases (64\%), while heterozygous $\mathrm{W} / \Delta$ was detected in 3 cases (6\%). A polymorphism (deletion) was uncovered in 4 cases. The allelic distribution was found to be $78 \%$ for $W$ and $22 \%$ for $\Delta$. The comparisons of genotype and allele frequencies between the early (before 65 years) and late onset (older than 65 years) as well as between male and female patients with $A D$ are presented in Table I. Statistically significant differences were not found.

The genotype TT in A2M exon 24 of the control group was detected in $52 \%$, TC in $30 \%$ and CC in $18 \%$ instances. In the control group the allelic distribution was as follows: T $67 \%$ and $\mathrm{C} 33 \%$. In AD the TT genotype in A2M exon 24 was found in 19 patients (38\%), TC in 19 individuals (38\%) and CC in 12 cases (29\%), and the allelic distribution was C $43 \%$ and T $57 \%$. The genotype and allele frequencies, divided according to gender, in early onset $A D$ are presented in Table II. Significant differences were detected between the subgroup of males in early onset $A D$ and the controls, as well as between the subgroup of females with late onset $A D$ and the respective controls.

\section{Discussion}

The molecular basis of $A D$ is of general interest and in recent years has been broadly discussed in

Table I. Genotype and allele frequencies for alpha-2-macroglobulin (A2M) exon 18 in Alzheimer disease and control groups

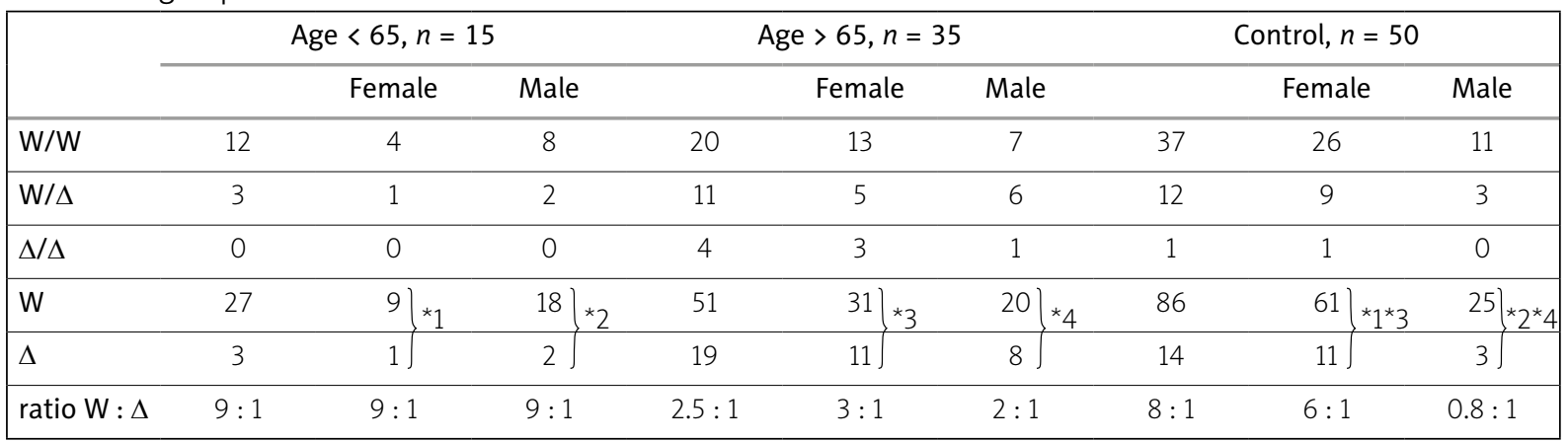

$O R=0.6162 ; p=0.6609\left(^{*} 1\right)$

$O R=0.9259 ; p=0.9364\left({ }^{*} 2\right)$

$O R=1.9677 ; p=0.1585\left({ }^{*} 3\right)$

$O R=3.3333 ; p=0.1040\left({ }^{*} 4\right)$ 
Table II. Genotype and allele frequencies for alpha-2-macroglobulin (A2M) exon 24 in Alzheimer disease and control groups

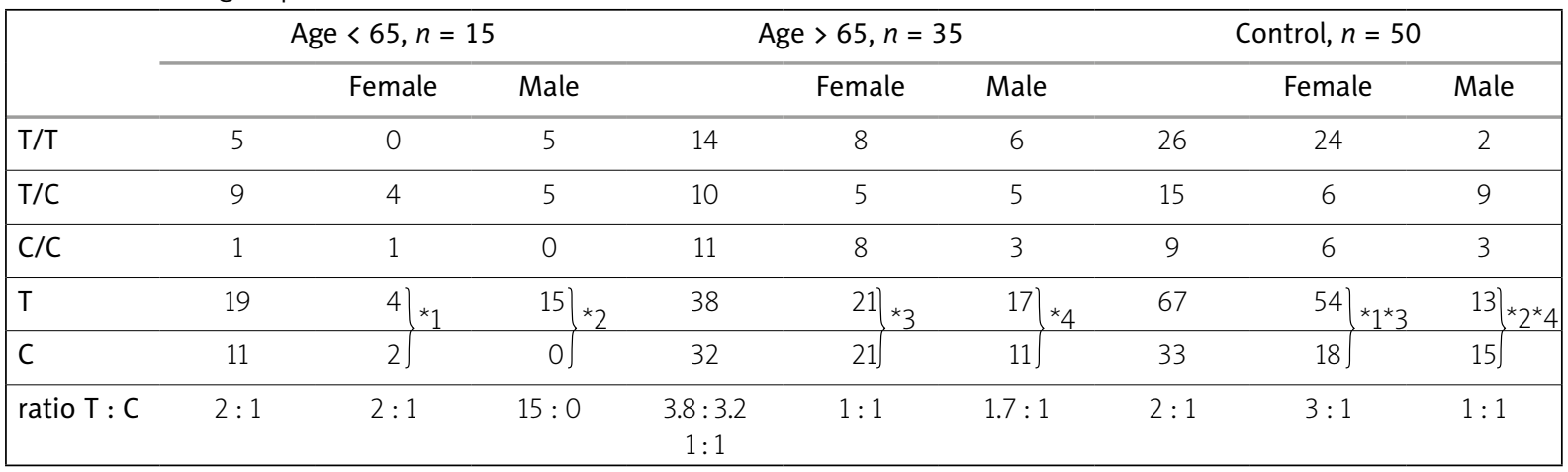

$O R=15000 ; p=0.6551\left({ }^{*} 1\right)$

$O R=0.02810 ; p=0.0161\left({ }^{*} 2\right)$

$O R=3.0000 ; p=0.0076\left({ }^{\star} 3\right)$

$O R=0.5608 ; p=0.2855(* 4)$

very interesting review papers $[1,2,18,19]$. Among several genetic factors which have been implicated in $A D$, only a few are thought to be causative for the disease. In the majority of sporadic AD cases, genetic factors act as predisposing agents, without the capacity to induce the disease but able to increase the risk of disease above that found in the general population. They may also interact among themselves to further enhance the probability of inducing the disease (synergic effect) [21].

In our studies we have used the typical approach to evaluate the genetic contribution to the risk of $A D$ by analyzing the frequency distribution of the allelic variants at polymorphic sites of the candidate gene, $\mathrm{A} 2 \mathrm{M}$, in cases of the disease and in controls. Alpha2-macroglobulin is a serum pan-protease inhibitor, also expressed in the brain, which has been implicated in $A D$ on the basis of its ability to mediate the clearance and degradation of $A \beta$, the major component of $\beta$-amyloid deposits. Alpha-2-macroglobulin is a component of senile plaques. The $A 2 M$ gene, mapped to chromosome $12 \mathrm{p}$, became a candidate as a disease locus for late-onset AD. Based on the positional information about the candidate gene, Blacker et al. [5] focused on a 5 bp deletion/insertion polymorphism of the A2M gene, located in the 5' splice site of exon 18. By using a family-based association test method, they found an association between the deletion allele (A2M-D) and late-onset AD. With a deletion, $A 2 M$ may be less effective in $\beta$-amyloid binding and clearance and in preventing its deposition in senile plaques. Sequencing of the RT-PCR products from the deletion and insertion homozygotes revealed no alteration in sequence from that expected, despite the loss of $5 \mathrm{bp}$ adjacent to exon 18. These molecular findings suggest that A2M deletion might be nonfunctional [6].

In our studied material we have not found any clear-cut differences in the frequency of genotype and allele frequency between $A D$ and controls. Significant differences were noted only in early onset $A D$ in males and for old onset disease in females. The deletions were found more frequently in $A D$; however, they were found in only a small proportion of studied patients.

There are three biological manifestations of the $A \beta-A 2 M$ interactions that may be directly relevant to the etiology of $A D$ [13]. First, the interaction between $A 2 M$ and $A \beta$ prevents $A \beta$ fibril formation and fibril-associated neurotoxicity. Secondly, protease activation of $A \beta-A 2 M$ complexes or protease activation of $A 2 M$ followed by $A \beta$ binding can promote the protease-mediated degradation of $A 2 M$ bound $A \beta$. And thirdly, protease activated $A \beta-A 2 M$ complexes may undergo LPR-mediated endocytosis followed by trafficking of $A \beta$ to lysosomes for degradation. The established late-onset risk factor ApoE $\varepsilon 4$ accelerates $A \beta$ deposition, and $A p o E$ is found in a complex with $\mathrm{A} 2 \mathrm{M}$ in plasma. Taken together, these findings indicate that $A 2 M$ is not the only biological candidate gene for $A D$ determination. So far, only the ApoE $\varepsilon 4$ allele is known to be a genetic risk factor for the later onset sporadic AD.

Similar negative results in the Polish population were obtained in studies of CR1, PICALM and CLU gene polymorphisms [12]. Therefore the slightly positive results obtained in studies by Bednarska-Makaruk et al. [4] are very interesting. The authors con- 
cluded that paraoxonase 1 (PON1) gene promoter polymorphism may have a role in $A D$ development. However, the role seems to be only an additional one.

\section{Disclosure}

\section{Authors report no conflict of interest.}

\section{References}

1. Armstrong RA. On the 'classification' of neurodegenerative disorders: discrete entities, overlap or continuum? Folia Neuropathol 2012; 50: 201-218.

2. Armstrong RA. What causes Alzheimer's disease? Folia Neuropathol 2013; 51: 169-188.

3. Bagli M, Papassotiropoulos A, Jessen F, Schmitz S, Rao ML, Maier W, Heun R. Identical distribution of the alpha 2-macroglobulin pentanucleotide deletion in subjects with Alzheimer disease and controls in a German population. Am J Med Genet 2000; 96: 775-777.

4. Bednarska-Makaruk ME, Krzywkowski T, Graban A, LipczyńskaŁojkowska W, Bochyńska A, Rodo M, Wehr H, Ryglewicz DK. Paraoxonase 1 (PON1) gene $-108 \mathrm{C}>T$ and p.Q192R polymorphisms and arylesterase activity of the enzyme in patients with dementia. Folia Neuropathol 2013; 51: 111-119.

5. Blacker D, Wilcox MA, Laird NM, Rodes L, Horvath SM, Go RC, Perry R, Watson B Jr,Basset SS, McInnisMG, Albert MS, Hyman BT, Tanzi RE. Alpha-2 macroglobulin is genetically associated with Alzheimer disease. Nat Genet 1998; 19: 357-360.

6. Blennow K, Ricksten A, Prince JA, Brookes AJ, Emahazion T, Was slavik C, Bogdanovic N, Andreasen N, Båtsman S, Marcusson J, Nägga K, Wallin A, Regland B, Olofsson H, Hesse C, Davidsson P, Minthon L, Jansson A, Palmqvist L, Rymo L. No association between the alpha2-macroglobulin (A2M) deletion and Alzheimer's disease, and no change in A2M mRNA, protein, or protein expression. J Neural Transm 2000; 107: 1065-1107.

7. Dodel RC, Du Y, Bales KR, Gao F, Eastwood B, Glazier B, Zimmer R, Cordell B, Hake A, Evans R, Gallagher-Thompson D, Thompson LW, Tinklenberg JR, Pfefferbaum A, Sullivan EV, Yesavage J, Alstiel L, Gasser T, Farlow MR, Murphy GM Jr, Paul SM. Alpha2 macroglobulin and the risk of Alzheimer's disease. Neurology 2000; 54: 438-442.

8. Halimi G, Duplan L, Bideau C, Iniesta D, Berthézène P, Oddoze C, Verdier JM, Michel B, Bergé-Lefranc JL. Association of APOE promoter but not A2M polymophisms with risk of developing Alzheimer's disease. Neuroreport 2000; 11: 3599-3601.

9. Higuchi S, Matsushita S, Nakane J, Arai H, Matsui T, Urakami K, Yuzuriha T, Takeda A. Alpha2-macroglobulin gene polymorphisms show racial diversity and are not associated with Alzheimer's disease. Neuroreport 2000; 11: 1167-1171.

10. Janka Z, Juhász A, Rimanóczy A, Boda K, Márki-Zay J, Palotás M, Kuk I, Zöllei M, Jakab K, Kálmán J. Alpha2-macroglobulin exon 24 (Val-1000-Ile) polymorphisms is not associated with late-onset sporadic Alzheimer's dementia in the Hungarian population. Psychiatr Genet 2002; 12: 49-54.
11. Jhoo JH, Kim KW, Lee DY, Lee KU, Lee JH, Kim SY, Youn JC, Woo JI. Association of alpha-2-macroglobulin deletion polymorphism with sporadic Alzheimer's disease in Koreans. J Neurol Sci 2001; 184: 21-25.

12. Klimkowicz-Mrowiec A, Sado M, Dziubek A, Dziedzic T, Pera J, Szczudlik A, Slowik A. Lack of association of CR1, PICALM and CLU gene polymorphisms with Alzheimer disease in a Polish population. Neurol Neurochir Pol 2013; 47: 157-160.

13. Kovacs DM. Alpha2-macroglobulin in late-onset Alzheimer's disease. Exp Gerontol 2000; 35: 473-479.

14. Li J, Liu Y, Kim T, Min R, Zhang Z. Gene expression variability within and between human populations and implications toward disease susceptibility. PLoS Comput Biol 2010; 6: 1-10.

15. Lukiw WJ. Variability in micro RNA (miRNA) abundance, speciation andcomplexity amongst different human populations and potential relevance toAlzheimer's disease (AD). Front Cell Neurosci 2013; 7: 1-4.

16. Myllykangas L, Polvikoski T, Sulkava R, Verkkoniemi A, Crook R, Tienari PS, Pusa AK, Niinistö L, O`Brien P, Kontula K, Hardy J, Haltia M, Pérez-Tur J. Genetic association of alpha2-macroglobulin with Alzheimer's disease in a Finnish elderly population. Ann Neurol 1999; 46: 382-390.

17. Nacmias B, Tedde A, Cellini E, Forleo P, Orlacchio A, Guarnieri BM, Petruzzi C, D’Andrea F, Serio A, Sorbi S. Alpha2-macroglobulin polymorphism in Italian sporadic and familial Alzheimer's disease. Neurosci Lett 2001; 16: 9-12.

18. Pluta R, Kocki J, Maciejewski R, Ułamek-Kozioł M, Jabłoński M, Bogucka-Kocka A, Czuczwar SJ. Ischemia signalling to Alzheimer-related genes. Folia Neuropathol 2012; 50: 322-329.

19. Šerý O, Povová J, Mišek I, Pešák L, Janout V. Molecular mechanisms of neuropathological changes in Alzheimer's disease: a review. Folia Neuropathol 2013; 51: 1-9.

20. Shi J, Ma C, Lao H, Feng R, Guo Y, Mu N, Li Q, Tan Y, Wang D. No evidence for association between the alpha 2-macroglobulin polymorphism and Alzheimer's disease in the Han Chinese. Zhonghua Yi Xue Yi Chuan Xue Za Zhi 2001; 18: 299-302.

21. Styczynska M, Religa D, Pfeffer A, Luczywek E, Wasiak B, Styczynski G, Peplonska B, Gabryelewicz T, Golebiowski M, Kobrys M, Barcikowska M. Simultaneous analysis of five factors in Polish patients with Alzheimer's disease. Neurosci Lett 2003; 344: 99-102.

22. Wang X, Luedecking EK, Minster RL, Ganguli M, DeKosky ST, Kamboh MI. Lack of association between alpha2-macroglobulin polymorphisms and Alzheimer's disease. Hum Genet 2001; 108: 105-108.

23. Zappia M, Cittadella R, Manna I, Nicoletti G, Andreoli V, Bonavita S, Gambardella A, Quattrone A. Genetic association of alpha2macroglobulin polymorphisms with AD in southern Italy. Neurology 2002; 59: 756-758. 